\title{
"Biosphere carbon stock management: addressing the threat of abrupt climate change in the next few decades." By Peter Read. An editorial comment
}

\author{
Catrinus J. Jepma
}

Received: 11 January 2008 /Accepted: 21 January 2008 / Published online: 21 January 2008

(C) The Author(s) 2008

Read's (2008) essay on the option of biosphere carbon stock management (BCSM) nicely connects a number of climate-related themes which he has extensively published on during the past few decades: concern about abrupt climate change (ACC) due to system nonlinearities; inclusion of ACC in the precautionary principle; the underestimation of the short-term contribution to addressing climate change when the use of bio energy would significantly increase; the carbon capture potential of investment in undercapitalised, often degraded land; the potential of 'negative emissions scenarios' by linking biomass production to carbon capture and storage (CCS); and, finally, the point that emissions caps would in many respects be inferior to obligations to introduce policy-desirable technologies.

The basic argument he unfolds in his essay is quite straightforward: the maximum impact of an 'aggressive' mitigation-oriented climate policy regime (i.e. a regime beyond the most ambitious publicly stated mitigation targets) is $\mathrm{CO}_{2}$-stabilisation at $400-450 \mathrm{ppm}$ by 2050-2100. Only a few people believe such a stabilisation can be achieved. Consequently, one should be prepared to face stabilisation of emissions at (significantly) higher levels. Because of the immanent threat of ACC, the precautionary principle should be applied not only to deal with the risks of climate change, but also to deal with the risk of abrupt climate change. In order to achieve lower emission levels sooner, a more extensive policy package is required than what we have been witnessing thus far (at least in the public statements). The best option for such a package would be BCSM, combined with CCS.

The essay raises a number of questions:

1. Is it conceivable that in the near future both policy makers and the broader public become equally aware of ACC as they have now become of the climate change issue? I presume that the answer to that is 'yes' when much of the recent literature on the issue is taken seriously, i.e. that there is at least a chance that processes get out of control. The present general concern about climate change has emerged during roughly the past decade (or, according to some, the last few years) after the first scientific and political work had been completed during the end of the 1980s and the early 1990s (IPCC AR1/

C. J. Jepma $(\bowtie)$

Department of Economics, University of Groningen, P.O. Box 800,

9700 AV Groningen, The Netherlands

e-mail: c.j.jepma@rug.nl 
2 and UNCCC). In other words, within about two decades, climate change has gone through a process of a broad scientific assessment, which has resulted in the recognition of the topic as being a very serious issue at high political levels. A similar process could unfold with respect to ACC during the next few decades if a growing amount of convincing scientific evidence would demonstrate that non-linearities in the system may generate the risk that processes, which thus far have been perceived as linear, may escalate.

2. Next question: Does the assumption that ACC should not be ruled out imply that preventive action should be developed right away? In other words: what are the boundaries of the precautionary principle? Eventually, the answer to that question seems to be a moral one, although some would probably claim (as has, for instance, extensively been done with regard to the application of social discount rates or statistical values of ecosystems or human lives) that such parameter values can be determined quasi objectively. Irrespective of the position taken, it is a crucial point in Read's argument: if ACC is a possibility, then we should develop a matching policy action right away in order to be able to accelerate mitigation. In reaction to that, however, I would argue that if ACC cannot be ruled out as a serious future threat, it is important to prepare ourselves to take future action, but such action would not be necessarily needed already now. There is no use for the fire brigade to drive around if there is no fire yet. Nevertheless, should there be sufficient evidence that the risk of a fire exists, then one should prepare the equipment and train the firemen well in time so that they can act quickly enough, etc.

3. If action in the near future would be needed to reduce emissions much more quickly than anticipated thus far in even the most ambitious mitigation scheme, what would be the preferred scenario? Read's answer is clear: the 'only' option is the carbon stock management approach, BCSM, preferably combined with CCS. The main argument for this answer is that the BCSM potential has been so far underestimated or even "overlooked" despite the fact that the mitigation potential of the option is very significant with generally positive externalities. An obvious comment on this position is that, when assessing the optimal technology mix in a hypothetical near(er)-term declining $\mathrm{CO}_{2}$-concentration scenario, one should try to carry out an optimisation process based on knowledge of various technology cost functions, taking the various externalities, distributional impact and other boundary conditions into account, etc. Read has not tried to do that, which makes his strong reliance on BCSM + CSS at least partly based on the presumption that accelerating mitigation profiles on a sufficiently large scale cannot be achieved with the help of the classical mitigation mix of increasing energy efficiency, renewables, fuel switch, nuclear, etc. This observation may be correct, but the question remains how rapidly and cost-effectively emissions would come down (vis-à-vis realistic baselines) if e.g. serious efforts were undertaken to stimulate international transfers of technologies in conjunction with well-designed accommodating transition management in the receiving countries. Another option could be to assess the potential of using the ocean for enhanced biomass formation, etc. Also, it can be questioned whether it is correct to claim — as Read does - that, from a technological perspective, mitigation through land management is much easier than mitigation through reduction of fuel use.

But let us start again from Read's final argument that the likelihood of accelerating emission reduction on a large scale is probably highest when activating BCSM. Then, the next question is how realistic the claim - or as Read puts it somewhere in his essay 
'hope' - is that massive BCSM can really be implemented successfully and with the proclaimed effect? This question has already led to a bottom-up vs top-down discussion about the carbon stock management mitigation potential, which does not need to be repeated here. Basically, Read wants to activate biomass production on land, which is presently not used for serious economic activities (except for hunting, gathering and slash and burn agriculture), and help dwellers and others develop into biomass-for-energy farmers. Can this be achieved at a very significant scale?

It will not be easy to answer this question without serious additional research on the various behavioural and sociological, as well as legal aspects that such a shift/migration would involve. But also the issue of economic incentives would need to be addressed: why would a commonly poor traditional slash-and burn farmer in a developing country turn into a biomass producer for the wider, possibly worldwide, energy market?

It also raises the question of how such an activity would relate to the commonly nearest alternative, i.e. use the formerly un- or limitedly productive land to grow biomass for food. In fact, there is increasing evidence that it has become increasingly difficult for food production to keep pace with demand. There is no guarantee that what has been achieved globally between e.g. 1970 and 2005 will, and even can, happen again in the near future. Between 1970 and 2005, the population growth by about 2.8 billion people was accompanied by a more than sufficient $90 \%$ increase in grain production. In fact, the number of people suffering from hunger declined by about a quarter during this period (from some 1 billion to some 750 million). The success of this green revolution can be explained among others, next to technological factors, by the strong increase in the use of fertilizer in the developing world $(\times 4)$, the substantial extension of the area under irrigation $(\times 1.5)$, and the extension of the area for agriculture due to deforestation.

However, there is little reason to expect that the green revolution of the past 3-4 decennia can easily be repeated in the developing world. Not only does the IPCC expect that, due to climate change, the grain production in the developing world will be $15-45 \%$ less by 2080 than today's levels, it is also unlikely that the higher demand for food in developing countries due to a population increase of about 2 billion people between now and 2025 , can be met by food production in developing countries. The main reason for this is that there will be fewer quality areas for crop production available due to land losses caused by erosion (some 7 million hectares per annum), urbanisation, desertification (about one-third of land area threatened by that), salinisation (some 100 million hectares degraded), deforestation (some 10 million ha per annum), and lack of water (water demand for agriculture, some $65 \%$ of total demand is likely to increase from $2,600 \mathrm{~km}^{3}$ to $3,200 \mathrm{~km}^{3}$ in 2025 , which will be very hard to meet). Consequently, land, particularly land for agriculture in developing regions, will become increasingly scarce. Land problems in the industrialized area may be similar in a world that faces an estimate increase in the global demand for grains of $40-45 \%$ by 2025 compared to levels in 2000 . For meat, a $60-65 \%$ increase in demand is expected between 2000 and 2025. Food prices are therefore likely to increase as a trend, which may compete both directly and indirectly, with BCSM.

If these trends are realistic, in combination with a large-scale BCSM at the same time for climate policy reasons, conflicting claims - which we are facing already in various parts of the world - on land use seem to be very likely. Currently, biomass (some 55 EJ) covers some $15 \%$ of global energy needs (although the percentage is much higher in most of the developing countries, China/Brazil some 30\%, India some 45\%). Projections for 2025 differ widely (60-145 EJ), but still there is a common expectation that the share will increase. However, if one would use the conservative assumption that the current share of biomass in worldwide energy demand of appr. $15 \%$ would be maintained by 2025 , then the land area 
for biomass-for-energy production would have to increase by some 150 million hectares, and probably much more if low-productivity, formerly unused areas would be used for that. Given the food-related arguments just mentioned, it is hard to see this happen without serious and large-scale availability and ownership problems. This would come on top of the already ongoing discussions on the need to introduce biomass-for-energy production certification systems in order to prevent unsustainable biomass production further adding to the BCSM complexity.

It will not be easy-given the increasing claims on land for food production - to achieve Read's target, i.e. to achieve large-scale BCSM. Yet, if ACC would develop into the major issue that some believe it will become, creativity is needed. It is definitely true that large areas of land will remain unused even if the search for agricultural land becomes more intensive. So, Read's concept deserves to be taken up and above all researched further in order to see how successful BCSM could become in a future world, which, however, may face increasing difficulties to meet growing demand for food, water and energy.

Open Access This article is distributed under the terms of the Creative Commons Attribution Noncommercial License which permits any noncommercial use, distribution, and reproduction in any medium, provided the original author(s) and source are credited.

\section{References}

Read P (2008) Biosphere carbon stock management: addressing the threat of abrupt climate change in the next few decades. Clim Change 87:3-4, this issue 